\title{
Adverse perinatal outcomes associated with homelessness and substance use in pregnancy
}

\author{
Merry Little, Rajiv Shah, Marian J. Vermeulen, Alice Gorman, Darlene Dzendoletas, Joel G. Ray
}

Abstract

Background: Women who are homeless during pregnancy may be exposed to poor nutrition, violence and substance use, yet the health status of their newborn infants has not been systematically evaluated. We undertook a study to provide preliminary estimates of the risk of adverse perinatal outcomes among Canadian women who are homeless or marginally housed during pregnancy, and the effect of concomitant substance use.

Methods: We conducted a retrospective cohort study at a single downtown hospital from October 2002 to December 2004, involving women who, during pregnancy, were homeless or underhoused ( $n=80)$, substance users $(n=59)$ or neither $(n=3756)$. We noted neonatal measures such as birth weight and gestational age; the main study outcomes were preterm birth before 37 weeks' gestation, birth weight less than $2000 \mathrm{~g}$ and small for gestational age at birth.

Results: Homelessness or inadequate housing was associated with an odds ratio (adjusted for maternal age, gravidity and being a current smoker of tobacco) of 2.9 (95\% confidence interval [Cl] 1.4-6.1) for preterm delivery, 6.9 (95\% Cl 2.420.0) for infant birth weight under $2000 \mathrm{~g}$ and $3.3(95 \% \mathrm{Cl}$ 1.1-10.3) for delivery of a newborn small for gestational age. Adjusted odds ratios for substance use during pregnancy were similar. In the combined presence of an underhoused or homeless state and maternal substance use, the adjusted risk estimates were 5.9 (95\% Cl 1.9-18.5), 16.6 (95\% Cl 3.5-79.3) and $5.6(95 \% \mathrm{Cl} 1.1-28.7)$, respectively.

Interpretation: Homelessness and maternal substance use may reduce neonatal well-being through prematurity and low birth weight.

CMAJ 2005;173(6):615-8

I $\mathrm{t}$ is estimated that in the largest metropolitan areas in Canada, approximately 5 in 10000 people sleep in homeless shelters. Toronto Hostel Division statistics from 2002 indicate that 6900 youths stayed in shelters. People 16-24 years of age made up 22\% of all shelter residents; $50 \%$ of these were young women, about half of whom became pregnant. ${ }^{1,2}$

Access to adequate prenatal care can be problematic among homeless women. ${ }^{3}$ Beyond exposure to poverty and violence, some women may be undernourished or continue to use street drugs or alcohol during pregnancy. ${ }^{4-6} \mathrm{Al}-$ though a high rate of self-reported and premature delivery of low-birth-weight infants was documented among homeless women in California, ${ }^{3}$ the absence of any systematic collection of perinatal data at the time of delivery and lack of comparative controls likely biased that study.

Little is known about the health of infants born to Canadian women who are homeless or housed suboptimally and among whom there are higher rates of alcohol and illicit drug use (substance use), insufficient antenatal care and HIV infection. ${ }^{5,6}$ We completed a preliminary study of adverse perinatal outcomes in relation to inadequate housing at the time of delivery and also explored the additive influence of substance use during pregnancy.

\section{Methods}

We conducted a retrospective cohort study involving all women who delivered a live or stillborn infant after 20 weeks of gestation at St. Michael's Hospital, in ethnically diverse downtown Toronto. The hospital performs about 2500 obstetric deliveries per year and is equipped with a level II nursery. Under the Inner City Health Program, the hospital provides obstetric care to all women who are permanent residents, landed immigrants or refugees in Ontario, whether or not they have a valid provincial health card number or other form of health insurance.

Using the hospital's obstetric database, we evaluated all deliveries at St. Michael's Hospital from October 2002 through December 2004. As a routine part of each woman's peripartum care, maternal, obstetric and neonatal data are recorded on a standardized form by the patient's obstetrician, nurse and pediatrician. This form contains check-mark fields detailing many aspects of the pregnancy, including current substance use and whether a woman was underhoused or homeless just before delivery. Perinatal details include gestational age at delivery and infant birth weight. The form was designed to summarize ante-, intra- and postpartum and neonatal events, allowing caregivers at all levels to keep track of the course of both mother and newborn until discharge. Formal definitions of antenatal care, substance use and underhoused or homeless state are not detailed or enforced, however: correct recording of the data relies on both mother and caregiver. The obstetric database is maintained by a clinical nurse practitioner and updated daily by a data clerk.

The study outcomes of interest included infant preterm birth before 37 weeks' gestation, birth weight less than $2000 \mathrm{~g}$ and small for gestational age (SGA) at birth, defined as a weight below the 10th percentile for sex-specific gestational age.

Maternal and infant characteristics were presented as either means or rates. To explore the association between the study outcomes and homelessness or substance use, crude and adjusted 
odds ratios (ORs) and 95\% confidence intervals (CIs) were estimated with logistic regression. ORs were adjusted for maternal age, gravidity and being a current smoker of tobacco, defined a priori; these data were also available within the obstetric database. We based the inclusion of each covariate in the analysis on our completed work on Ontarian women ${ }^{7,8}$ and evidence from 1 previously published study suggesting that each covariate was a statistically significant and clinically important predictor of either preterm birth or low birth weight.

We assessed model fit using the Hosmer-Lemeshow test for goodness of fit. Collinearity was determined by examining the correlations between the covariates, and a correlation coefficient threshold of 0.80 was set to determine whether any variables defined a priori should be excluded from the model. All $p$ values were 2-sided, at a significance level of 0.05 .

Maternal identifiers were removed before abstraction from the database. The Research Ethics Board of St. Michael's Hospital granted permission to conduct this study.

\section{Table 1: Characteristics of 3836 women who gave birth at an inner-city hospital in Toronto, October 2002 through December 2004}

\begin{tabular}{|c|c|c|c|c|}
\hline \multirow[b]{2}{*}{ Characteristic } & \multicolumn{2}{|c|}{$\begin{array}{c}\text { Homeless or } \\
\text { inadequately housed }\end{array}$} & \multicolumn{2}{|c|}{ Current substance use } \\
\hline & $\begin{array}{c}\text { Absent } \\
n=3756\end{array}$ & $\begin{array}{c}\text { Present } \\
n=80\end{array}$ & $\begin{array}{c}\text { Absent } \\
n=3777\end{array}$ & $\begin{array}{c}\text { Present } \\
n=59\end{array}$ \\
\hline \multicolumn{5}{|c|}{ Maternal, current or during pregnancy } \\
\hline Proportion of cohort, \% & 97.9 & 2.1 & 98.5 & 1.5 \\
\hline Age, mean (SD), yr & $30.7(5.5)$ & $25.0(6.9)$ & $30.6(5.6)$ & $26.8(7.0)$ \\
\hline Gravidity, median (range) & $2(1-13)$ & $2(1-8)$ & $2(1-13)$ & $3(1-8)$ \\
\hline Cigarette smoking, \% & 1.6 & 38.5 & 1.4 & 62.0 \\
\hline Receiving social assistance, $\%$ & 1.5 & 43.8 & 1.7 & 36.0 \\
\hline Little or no antenatal care, $\%$ & 0.3 & 12.5 & 0.2 & 22.0 \\
\hline Substance use, \% & 1.0 & 28.5 & - & - \\
\hline \multicolumn{5}{|l|}{ Infant, at birth } \\
\hline Gestational age, mean (SD), wk & $39.0(1.7)$ & $38.2(2.8)$ & $39.0(1.7)$ & $38.0(2.7)$ \\
\hline Weight, mean (SD), g & $3329(538)$ & 3071 (892) & $3330(542)$ & 2835 \\
\hline
\end{tabular}

Note: $\mathrm{SD}=$ standard deviation

\section{Results}

The characteristics of all 3836 participants are presented in Table 1. More women who were reported in the database records as being homeless or underhoused were smokers and tended to be younger, more frequently in receipt of social assistance and more likely to have had little or no antenatal care than women with adequate housing. On average their infants were born nearly 1 week earlier and weighed some $260 \mathrm{~g}$ less than those of the control group. Similar demographic differences were seen for women recorded as being substance users, but their infants weighed nearly $500 \mathrm{~g}$ less at birth than those of nonusers.

In the main model, no collinearity was observed between the covariates of interest. Preterm birth occurred to over $19 \%$ of infants born to women with insufficient housing; when combined with substance use, the rate doubled (Table 2). The adjusted risk of preterm delivery was almost tripled among women affected by either homelessness or substance use, and among women with both risk factors was associated with about 6 times the risk among those in the control group. The risk of a homeless woman or substance user giving birth to an infant weighing less than $2 \mathrm{~kg}$ was $6-7$ times that in the control group; among mothers with both risk factors, this rose to 16.6 times. The respective ORs for SGA birth weight, compared with ORs of newborns of mothers in the control group, similarly rose from about 3 times among women with 1 risk factor to 5.6 times among those with both.

We conducted a post hoc analysis to determine whether receipt of social assistance and getting little or no antenatal care

Table 2: Risk of preterm birth and low infant birth weight in relation to maternal status for housing, substance use or both

\begin{tabular}{|c|c|c|c|c|c|c|c|c|c|}
\hline \multirow[b]{2}{*}{$\begin{array}{l}\text { Maternal } \\
\text { risk factor }\end{array}$} & \multicolumn{3}{|c|}{ Preterm birth $<37$ wk } & \multicolumn{3}{|c|}{ Infant birth weight $<2000 \mathrm{~g}$} & \multicolumn{3}{|c|}{ Small for gestational age* } \\
\hline & $\begin{array}{c}\text { Rate, } \\
\%\end{array}$ & $\begin{array}{l}\text { Crude OR } \\
(95 \% \mathrm{Cl})\end{array}$ & $\begin{array}{l}\text { Adjusted OR† } \\
(95 \% \mathrm{Cl})\end{array}$ & $\begin{array}{c}\text { Rate, } \\
\%\end{array}$ & $\begin{array}{l}\text { Crude OR } \\
(95 \% \mathrm{Cl})\end{array}$ & $\begin{array}{c}\text { Adjusted OR† } \\
(95 \% \mathrm{Cl})\end{array}$ & $\begin{array}{l}\text { Rate, } \\
\%\end{array}$ & $\begin{array}{l}\text { Crude OR } \\
(95 \% \mathrm{Cl})\end{array}$ & $\begin{array}{c}\text { Adjusted OR† } \\
(95 \% \mathrm{Cl})\end{array}$ \\
\hline $\begin{array}{l}\text { Homeless or } \\
\text { underhoused }\end{array}$ & 19.4 & $3.6(1.9-6.8)$ & $2.9(1.4-6.1)$ & 10.9 & $\begin{array}{l}7.6(3.3-17.2) \\
5.9(1.8-19.4) \ddagger\end{array}$ & $6.9(2.4-20.0)$ & 8.1 & $4.2(1.6-10.8)$ & $3.3(1.1-10.3)$ \\
\hline Factor absent & 6.3 & 1.0 (reference) & 1.0 (reference) & 1.6 & 1.0 (reference) & 1.0 (reference) & 2.0 & 1.0 (reference) & 1.0 (reference) \\
\hline $\begin{array}{l}\text { Current } \\
\text { substance use }\end{array}$ & 20.8 & $3.9(1.9-8.0)$ & $\begin{array}{l}2.7(1.1-6.5) \\
1.9(0.7-5.1) \neq\end{array}$ & 12.0 & $8.3(3.4-20.2)$ & $\begin{array}{l}6.4(1.7-23.8) \\
5.0(1.2-20.6) \ddagger\end{array}$ & 8.3 & $4.3(1.5-12.4)$ & $2.8(0.69-11.0)$ \\
\hline Factor absent & 6.3 & 1.0 (reference) & 1.0 (reference) & 1.6 & 1.0 (reference) & 1.0 (reference) & 2.0 & 1.0 (reference) & 1.0 (reference) \\
\hline $\begin{array}{l}\text { Both factors } \\
\text { present }\end{array}$ & 38.9 & $9.4(3.6-24.5)$ & $\begin{array}{l}5.9(1.9-18.5) \\
4.0(1.2-13.8) \neq\end{array}$ & 26.3 & $21.5(7.5-61.6)$ & $16.6(3.5-79.3)$ & 16.7 & $9.5(2.7-33.5)$ & $5.6(1.1-28.7)$ \\
\hline Both absent & 6.3 & 1.0 (reference) & 1.0 (reference) & 1.6 & 1.0 (reference) & 1.0 (reference) & 2.1 & 1.0 (reference) & 1.0 (reference) \\
\hline
\end{tabular}

Note: $\mathrm{OR}=$ odds ratio, $\mathrm{Cl}$ confidence interval.

*Defined as birth weight below the 10th percentile for gestational age, specific to sex.

†Adjusted for maternal age, gravidity and current cigarette smoking.

ҒOR attenuated by more than $20 \%$ in post hoc analysis after addition of receipt of social assistance and little or no antenatal care to the multivariate model 
accounted for the effect of homelessness and substance use. The main effects (i.e., the ORs) were attenuated by more than $20 \%$ in 4 analyses (indicated in Table 2), but only preterm birth among substance users lost its statistical significance.

In the modified multivariate analysis examining inadequate maternal housing, preterm birth was also significantly associated with getting little or no antenatal care (adjusted OR 4.4, 95\% CI 1.4-14.0), but not with receipt of social assistance (adjusted OR 0.98, 95\% CI 0.42-2.3). Similar patterns were seen in our analysis of substance use, both alone and in combination with inadequate housing. When we introduced low infant birth weight and SGA into the multivariate models of inadequate housing, substance use, or the 2 together, neither factor had any significant association with receipt of social assistance or poor antenatal care.

\section{Interpretation}

Within a setting where health care is available to everyone, we found that inadequate maternal housing and substance use during pregnancy conferred an increased risk of unfavourable perinatal events. Since these absolute risk estimates approximate those among women with prepregnancy diabetes mellitus ${ }^{7}$ and chronic hypertension, ${ }^{8}$ they suggest that pregnant women who are homeless or engage in substance use be considered high risk.

The data set we used depended on accurate recording of maternal residence and substance use, which was left to the discretion of the mother and her delivery caregiver. A clear limitation of our study method was that we did not ascertain duration of homelessness before delivery. We could not identify a participant's ethnicity (which may, for example, influence her access to prenatal care), ${ }^{9}$ nor did we include a proper measure of socioeconomic status. Differences in receipt of social assistance or whether adequate antenatal care was obtained may partly explain the association between housing status and perinatal outcome; maternal education (not assessed in our study) could similarly affect the risk of preterm birth and SGA birth weight. ${ }^{10}$ Although our study was limited to a single centre in a densely populated area of low-income neighbourhoods, the $6.3 \%$ rate of preterm delivery seen in our control group was similar to Canada's national average. ${ }^{11}$ Likewise, the corresponding $19.4 \%$ rate among our underhoused or homeless cohort approximated the $18.5 \%$ self-reported rate from a Los Angeles survey. ${ }^{3}$

Maternal substance use during pregnancy, including crack cocaine, has been shown to adversely affect maternal placentation and fetal well-being. ${ }^{12}$ In conjunction with substance use, we observed a high rate of cigarette smoking, itself linked to preterm births ${ }^{13}$ and fetal growth restriction. ${ }^{14}$ Maternal undernutrition, too, may be more common among women who are homeless or substance users, which may also restrict fetal growth. ${ }^{14}$ The web of causes under- lying preterm delivery and low infant birth weight in women who report substance use or homelessness in pregnancy clearly requires a more detailed collection, validation and analysis of variables than those in our study.

The short-term effect of maternal homelessness on infant health may lead to long-term consequences. First, it is recognized that newborns who are small for their gestational age display lower academic achievement into adulthood than those of normal weight. ${ }^{15}$ Second, children reared in homeless shelters appear to experience high rates of emotional, cognitive and physical health problems. ${ }^{16,17}$

It would be reasonable to develop a rapid-response program in chosen shelters, community health centres and 1 or more local hospitals for early identification of pregnancies among homeless women. This ought to include the provision of immediate access to shelter, nutritious foods, prenatal care and addiction management. Reduced use of street drugs should be broadly encouraged, alongside methods to maintain sexual health, such as choice and use of contraceptives to reduce the risks of sexually transmitted infections and unwanted pregnancies. Safe, more permanent housing before delivery, along with financial, social and educational supports, would be the most enabling approach for a mother, her newborn child and, perhaps, her partner and her other children.

Further study is clearly needed to explore the specific mechanisms that affect the health of women who are inadequately housed during and after pregnancy and the health of their infants. ${ }^{18}$ Nevertheless, the need to minimize homelessness among Canadians is foremost.

This article has been peer reviewed.

From the Departments of Obstetrics and Gynecology (Little, Shah, Dzendoletas, Ray) and Medicine (Ray), St. Michael's Hospital; the Institute for Clinical Evaluative Sciences, Sunnybrook and Women's College Health Sciences Centre (Vermeulen); the Departments of Medicine and of Health Policy Management and Evaluation, University of Toronto (Ray); Toronto Public Health (Gorman); and Young Parents No Fixed Address (Little, Gorman, Dzendoletas), Toronto, Ont.

Competing interests: None declared.

Contributors: All authors were responsible for the study conception and design. Merry Little and Darlene Dzendoletas were responsible for data acquisition. Rajiv Shah, Marian Vermeulen and Joel Ray analyzed the data. Little, Vermeulen and Ray interpreted the data. Little and Ray drafted the article. All authors revised the article and gave final approval of the version to be published.

Acknowledgements: We are indebted to the mothers, nurses, physicians and midwives at St. Michael's Hospital who continue to contribute valuable information to the hospital's obstetric database.

Joel Ray was supported through a New Investigator Award by the Canadian Institutes of Health Research.

\section{References}

1. Basrur S. No fixed address: young parents on the street. Toronto: Board of Health; 1998.

2. Haley N, Roy E, Leclerc P, Boudreau JF, Boivin JF. Characteristics of adolescent street youth with a history of pregnancy. 7 Pediatr Adolesc Gynecol 2004; 17:313-20.

3. Stein JA, Lu MC, Gelberg L. Severity of homelessness and adverse birth outcomes. Health Psychol 2000;19:524-34.

4. Greene JM, Ringwalt CL. Pregnancy among three national samples of runaway and homeless youth. 7 Adolesc Health 1998;23:370-7. 
5. Wincup E, Buckland G, Bayliss R. Youth homelessness and substance use: report to the Drugs and Alcohol Research Unit. London (UK): Home Office Research, Development and Statistics Directorate; 2003.

6. Robrecht LC, Anderson DG. Interpersonal violence and the pregnant homeless woman. 7 Obstet Gynecol Neonatal Nurs 1998;27:684-91.

7. Ray JG, Vermeulen MJ, Shapiro JL, Kenshole AB. Maternal and neonata outcomes in pregestational and gestational diabetes mellitus, and the influence of maternal obesity and weight gain: the DEPOSIT study. Diabetes Endocrine Pregnancy Outcome Study in Toronto. Q7M 2001;94:347-56.

8. Ray JG, Burrows R, Vermeulen M, Burrows E. MOS HIP: McMaster Outcome Study of Hypertension in Pregnancy 1. Early Hum Dev 2001;64:129-43.

9. Rowe RE, Garcia J, Davidson LL. Social and ethnic inequalities in the offer and uptake of prenatal screening and diagnosis in the UK: a systematic review. Public Health 2004;118:177-89.

10. Fraser AM, Brockert JE, Ward RH. Association of young maternal age with adverse reproductive outcomes. N Engl 7 Med 1995;332:1113-7.

11. Joseph KS, Kramer MS, Marcoux S, Ohlsson A, Wen SW, Allen A, et al Determinants of preterm birth rates in Canada from 1981 through 1983 and from 1992 through 1994. NEngl 7 Med 1998;339:1434-9.

12. Addis A, Moretti ME, Ahmed Syed F, Einarson TR, Koren G. Fetal effects of cocaine: an updated meta-analysis. Reprod Toxicol 2001;15:341-69.

13. Shah NR, Bracken MB. A systematic review and meta-analysis of prospective studies on the association between maternal cigarette smoking and preterm delivery. Am 7 Obstet Gynecol 2000;182:465-72.

14. Kramer MS. Socioeconomic determinants of intrauterine growth retardation. Eur 7 Clin Nutr 1998;52(Suppl 1):S29-32.

15. Strauss RS. Adult functional outcome of those born small for gestational age: twenty-six-year follow-up of the 1970 British Birth Cohort. FAMA 2000;283 625-32.

16. San Agustin M, Cohen P, Rubin D, Cleary SD, Erickson CJ, Allen JK. The Montefiore community children's project: a controlled study of cognitive and emotional problems of homeless mothers and children. 7 Urban Health 1999; 76:39-50.

17. Burg MA. Health problems of sheltered homeless women and their dependent children. Health Soc Work 1994;19:125-31.

18. Haas JS, Fuentes-Afflick E, Stewart AL, Jackson RA, Dean ML, Brawarsky P, et al. Prepregnancy health status and the risk of preterm delivery. Arch Pediatr Adolesc Med 2005;159:58-63.

Correspondence to: Dr. Joel G. Ray, Departments of Medicine and of Obstetrics and Gynecology, St. Michael's Hospital, University of Toronto, 30 Bond St., Toronto ON M5B 1W8; fax 416 864-5485; rayj@smh.toronto.on.ca

\section{Holiday Review 2005 Call for submissions}

Hilarity and good humour ... help enormously in both the study and the practice of medicine ... [I]t is an unpardonable sin to go about among patients with a long face.

— William Osler

Yes, that's right, it's already time to send us your creative contributions for CMAJ's Holiday Review 2005. We're looking for humour, spoofs, personal reflections, history of medicine, off-beat scientific explorations and postcards from the edge of medicine.

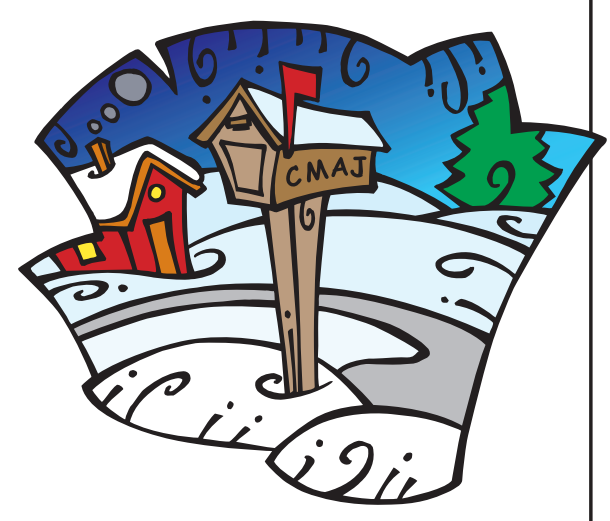

Send your offerings through our online manuscript tracking system (http://mc.manuscriptcentral.com/cmaj). Articles should be no more than 1200 words; photographs and illustrations are welcome. Please mention in your cover letter that your submission is intended for this year's Holiday Review.

The deadline for submissions is Sept. 20, 2005. 